\title{
Safety Profile of Nutraceuticals Rich in Coumarins: An Update
}

\author{
Simona Codruta Heghes ${ }^{1}$, Oliviu Vostinaru ${ }^{2 *}$, Cristina Mogosan ${ }^{2}$, Doina Miere ${ }^{3}$, \\ Cristina Adela luga ${ }^{1,4}$ and Lorena Filip ${ }^{3}$
}

${ }^{1}$ Department of Drug Analysis, Iuliu Hatieganu University of Medicine and Pharmacy, Cluj-Napoca, Romania, ${ }^{2}$ Department of Pharmacology, Physiology and Physiopathology, I liu Hatieganu University of Medicine and Pharmacy, Cluj-Napoca, Romania, ${ }^{3}$ Department of Bromatology, Hygiene, Nutrition, Iuliu Hatieganu University of Medicine and Pharmacy, Cluj-Napoca, Romania, ${ }^{4}$ Department of Proteomics and Metabolomics, Research Center for Advanced Medicine-MedFUTURE, luliu Hațieganu University of Medicine and Pharmacy, Cluj-Napoca, Romania

Coumarins are a family of benzopyrones largely distributed in the natural kingdom, being present in the seeds, fruits, flowers, or roots of various plant species. Natural coumarin compounds are found in significant concentrations in some herbs or spices used as nutraceuticals, but they are also present in cosmetics or household products, due to their pleasant odor. Therefore, an accidental exposure to high doses of coumarins, could lead to the development of harmful effects in some patients. This review summarizes the latest published data from preclinical and clinical studies with natural coumarins, focused on the investigation of general and specific toxicity, with the aim of a better understanding of the safety profile of these valuable compounds. Regulatory aspects concerning the use of natural coumarins in several world regions are also reviewed.

Keywords: coumarins, nutraceuticals, acute toxicity, hepatotoxicity, phototoxicity

\section{INTRODUCTION}

Nutraceuticals are bioactive substances which have become increasingly popular in the last 2 decades being used worldwide for health promotion and the prevention of various diseases. They are represented by numerous phytochemicals but also fatty acids, amino acids or probiotics/prebiotics and may be responsible for a variety of biological effects (Nahar et al., 2021).

In the larger category of nutraceuticals, natural coumarins play an important role, being present in high concentrations in several dietary plant species, like tonka beans (Dipteryx odorata (Aubl.) Forsyth $\mathrm{f}$ [Fabaceae]) where they have been originally discovered in 1820, or cinnamon (Cinnamomum verum J. Presl [Lauraceae]), but also in a variety of foodstuffs like olive and soy oils, coffee, nuts, wine, and green tea (Lončar et al., 2020).

Many natural coumarins have been successfully tested for an array of pharmacological properties like anti-inflammatory, antioxidant, antimicrobial, antidepressant, neuroprotective or antitumoral effects (Srikrishna et al., 2018). Additionally, several natural coumarins have served as scaffolds for the development of authorized drugs like warfarin, other drug candidates with different pharmacological properties being constantly developed (Bansal et al., 2013).

Although several articles and reviews focused on the presentation of important chemical and pharmacotherapeutic aspects regarding natural coumarins have been already published (Venugopala et al., 2013; Annunziata et al., 2020;Sharifi-Rad et al., 2021), the safety profile of coumarins was not thoroughly reviewed to present date. From a toxicological point of view, the presence of several natural coumarins in spices like cassia cinnamon which is widely used for preparation of pastries, cakes, or sweet biscuits, but also in cosmetics like perfumes or sunscreens, means that multiple routes 


\section{FOODS/PLANTS COUMARINS}
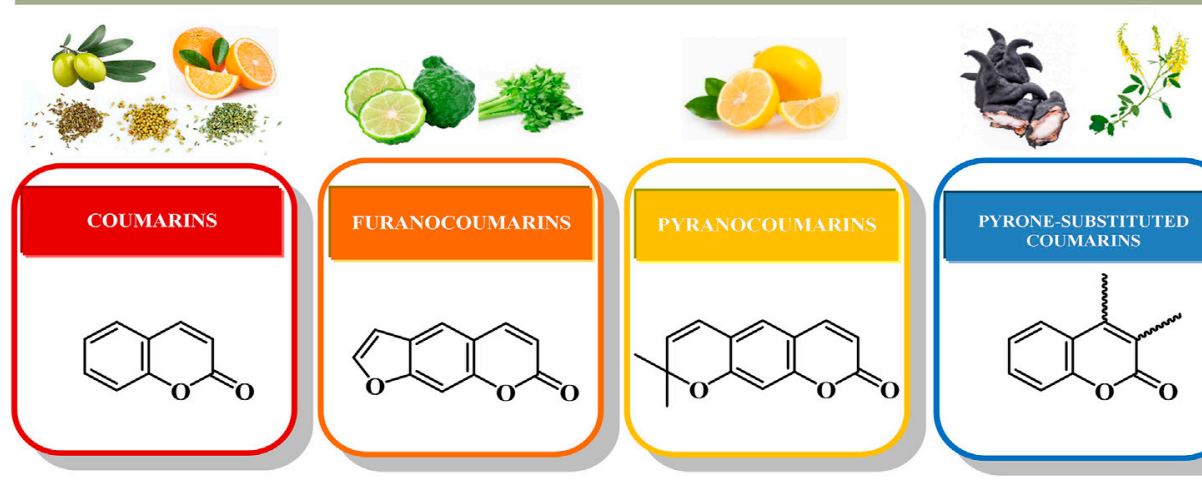<smiles>O=c1ccc2cc(O)c(O)cc2o1</smiles><smiles>O=c1ccc2cc3ccoc3cc2o1</smiles><smiles></smiles><smiles>O=c1oc2ccccc2c(O)c1Cc1c(O)oc2ccccc2c1=O</smiles><smiles>COc1ccc2ccc(=O)oc2c1CC=C(C)CO</smiles><smiles>COc1c2ccoc2cc2oc(=O)ccc12</smiles><smiles>CC1(C)C=Cc2c(ccc3ccc(=O)oc23)O1</smiles><smiles>O=c1ccc2ccc(O)cc2o1</smiles><smiles>Cc1cc(=O)oc2c1ccc1occc12</smiles><smiles>CCC(C)C(=O)OC1C(OC(C)=O)c2c(ccc3ccc(=O)oc23)OC1(C)C</smiles><smiles>Cc1c(C)c2ccccc2oc1=O</smiles><smiles>COc1cc2ccc(=O)oc2cc1O</smiles>

FIGURE 1 | Chemical structures of the main classes of natural coumarins.

of human exposure to natural coumarins have been described, with a possible oral, pulmonary, or skin absorption and subsequent development of toxic effects. Therefore, the aim of this review was to present the latest available data from preclinical and clinical studies with natural coumarins, regarding both general toxicity and specific organ toxicities, with additional mechanistic explanations, in order to increase the awareness of healthcare and food industry professionals for a safer use of these valuable compounds.

\section{NATURAL COUMARINS: TYPES AND SOURCES}

\section{Structure and Classification}

Coumarins are one of the most important classes of chemical compounds synthesized by plants, being part of the family of benzopyrones (Sarker and Nahar, 2017). Coumarin backbone
(Figure 1) consists of an aromatic benzene ring in a conjugated system, which is fused with a-pyrone (lactone ring). The structure is rich in electrons and capable to react with different molecules as enzymes and receptors, which leads to potent medicinal effects (Önder, 2020).

Currently, more than 1800 coumarin-derived compounds were described (Akkol et al., 2020; Lončar et al., 2020). Naturally occurring coumarins are subdivided in different classes based on their chemical diversity and complexity: simple coumarins (esculetin, scopoletin, umbelliferone), furanocoumarins (psoralen, bergapten, angelicin), pyranocoumarins (xanthyletin, seselin) and coumarins substituted in the pyrone ring, as biscoumarins (dicoumarol) or benzocoumarins (urolithins) (Annunziata et al., 2020) (Figure 1). Additionally, simple coumarins like umbelliferone or can be linked to a $\mathrm{C}_{15}$ terpene moiety, forming sesquiterpene coumarins like umbelliprenin (Gliszczynska and Brodelius, 2011). 
TABLE 1 | Main coumarins and their vegetal sources.

\section{Plant species}

Coumarins

\section{References}

Apiaceae/Umbelliferae

Anethum graveolens (L.)

(Dill)

Angelica archangelica (L.)

(Angelica)

Apium graveolens (L.)

(Celery)

Coriandrum sativum (L.) (Coriander)

Cuminum cyminum (L.) (Cumin)

Daucus carota (L.)

(Carrot)

Foeniculum vulgare Mill. (Fennel)

Pastinaca sativa (L.)

(Parsnip)

Petroselinum crispum (Mill.) Fuss

(Parsley)

Pimpinella anisum (L.) (Aniseed)

Rutaceae

Aegle marmelos (L.) Corrêa

(Bael fruit)

Citrus $x$ aurantiifolia (Christm.) Swingle

(Lime)

Citrus $x$ limon (L.) Osbeck

(Lemon)

Citrus $x$ sinensis (L.) Osbeck

(Sweet orange)

Citrus x paradisi Macfad. (Grapefruit)

Asteraceae/Compositae

Arnica montana (L.) (Arnica)

Chamaemelum nobile (L.) All

(Roman Chamomile)

Cichorium intybus (L.) (Chicory)

Matricaria chamomilla (L.)

(Chamomille)

Fabaceae/Leguminosae

Dipteryx odorata (Aubl.) Forsyth $f$

(Tonka Bean)

Glycyrriza glabra (L.) (Liquorice)

Trigonella foenum-graecum (L.)

(Fenugreek)

Moraceae

Oleae europaea (L.)

(Olive)

Ficus carica (L.)

(Fig)

Araliaceae

Eleutherococcus senticosus (Rupr. \&

Maxim.) Maxim

(Siberian Ginseng)

Lamiaceae/Labiadae

Ocimum basilicum (L.)

(Basil)

Lauraceae

Cinnamomum sp. (Cinnamon)

Persea americana Mill. (Avocado)

Tiliaceae

Tilia cordata Mill. (Linden)

Urticaceae

Urtica dioica (L.)

(Nettle)
Esculetin, scopoletin, furanocoumarin, oxypeucedanin, oxypeucedanin hydrate, falcarindiol

Angelicin, osthole, bergapten, imperatorin, isoimperatorin, oreoselone,

oxypeucedanin, psoralen, umbelliferone, xanthotoxin, xanthotoxol, umbelliprenin

Esculetin, bergapten, celerin, celereoside, isoimperatorin, isopimpinellin, osthenol, seselin, scopoletin, psoralen, umbelliferone, xanthotoxin

Coumarin 7-substituted derivatives

Coumarin

Bergapten, isopimpinellin, umbelliferone, xanthotoxin

Scopoletin, bergapten, imperatorin, 8-methoxypsoralen, psoralen Angelicin, bergapten, isopimpinellin, oxypeucedanin hydrate, xanthotoxin, imperatorin, psoralen

Bergapten, oxypeucedanin, 8-metoxypsoralen, imperatorin, isoimperatorin, isopimpinellin, psoralen

Bergapten, scopoletin, umbelliferone, umbelliprenine

Angelicin, umbelliferone, scopoletin, marmesinin, 8-hydroxypsoralen, marmelosin

Bergamottin, 5-geranyloxy-7-Methoxycoumarin, imperatorin, isoimperatorin, isopimpinellin, limettin, marmesin, oxypeucedanin hydrate, phellopterin, scoparone Limettin, 5-geranyloxy-7-methoxycoumarin, oxypeucedanin hydrate,

byakangelicol, oxypeucedanin, 8-geranyloxypsoralen, bergamottin, umbelliferone, heraclenin, phellopterin, osthole, auraptene, isopimpinellin, bergapten

Herniarin, scopoletin, scoparone, umbelliferone, xanthyletin, bergaptol

Bergamottin, auraptene, limettin, scopolin, bergapten, bergaptol, isopimpinellin, osthole

Scopoletin, umbelliferone

Scopolin (7- $\beta$-D-glucopyranosyl-scopoletin), umbelliferone, herniarin, scopoletin

Umbelliferon, esculetin (6,7-dihydrocumarin) scopoletin, esculetin and cichorin Umbelliferone, herniarin, skimmin, daphin, daphnetin

Esculin, esculetin

Glycycoumarin, isoglycycoumarin, licopyranocoumarin, isotrifoliol, glycyrol, glycyrurol, licoarylcoumarin, glycyrin

Hymecromone, trigocoumarin, trigoforin, scopoletin

Esculetin, scopoletin, esculin

Umbelliferone, psoralen, bergapten

Isofraxidin

Esculetin, esculin, coumarin, ocimarin

Coumarin, scopoletin

C. zeylanicum has a low content compared with other species

Scopoletin

Scopoletin

Umbelliferone, esculetin, scopoletin
Kovač-Bešović and Durić, (2003); Kaur and Arora, (2010)

Kumar et al., 2013; Forycka and Buchwald, (2019)

Garg et al., 1979; Najda et al., 2015;

Arsenov et al., 2021

Sharifi-Rad et al. (2021)

Rebey et al. (2012)

Ozçelik and Kusmenoglu, (2004); Kenari et al., 2021

Kaur and Arora, (2010); Yang et al., 2015

Kenari et al. (2021)

Manderfeld et al., 1997; Arsenov et al.,

2021

Sun et al. (2019)

Avula et al. (2016)

Dugrand et al., 2013; Dugrand-Judek et al., 2015

Dugrand et al., 2013; Dugrand-Judek et al., 2015

Dugrand et al., 2013; Dugrand-Judek et al., 2015

Dugrand et al., 2013; Dugrand-Judek et al., 2015

Kriplani et al. (2017)

European Medicines Agency, (2011)

Das et al., 2016; Aisa et al., 2020

Petrul'ová-Poracká et al. (2013)

Oliveros-Bastidas et al. (2013)

Zang, (2020)

Dini and Laneri, (2021)

Hashmi et al., 2015; European Medicines Agency, (2017)

Ammar et al. (2015)

Guo et al. (2019)

Zahran et al. (2020)

Wang et al., 2013; Ananthakrishnan et al., 2018

Bhuyan et al. (2019)

Arcos et al. (2006)

Esposito et al., 2019; Repajić et al., 2021 
TABLE 2 | Toxicological aspects concerning natural coumarins.

\begin{tabular}{|c|c|c|c|}
\hline Type of toxicity & $\begin{array}{c}\text { Type of study } \\
\text { (preclinical model/clinical test/ } \\
\text { case report) }\end{array}$ & Findings & References \\
\hline \multirow[t]{5}{*}{ General toxicity } & Acute toxicity of coumarin in mice & Oral LD50 of $196-780$ mg/kg with signs of liver toxicity & Lake, (1999) \\
\hline & $\begin{array}{l}\text { Subchronic toxicity of coumarin in } \\
\text { Sprague-Dawley rats }\end{array}$ & $\begin{array}{l}\text { Signs of liver toxicity after } 13 \text { weeks of oral administration of doses } \\
\text { over } 50 \mathrm{mg} / \mathrm{kg}\end{array}$ & Lake and Grasso, (1996) \\
\hline & Acute toxicity of osthole in mice & Intraperitoneal LD50 of $710 \mathrm{mg} / \mathrm{kg}$ & Shokoohinia et al. (2017) \\
\hline & Acute toxicity of esculetin in mice & Low toxicity with oral LD50 over 2000 mg/kg & Tubaro et al. (1988) \\
\hline & Acute toxicity of auraptene in rats & $\begin{array}{l}\text { No mortality or signs of toxicity after oral administration of } \\
125-2000 \mathrm{mg} / \mathrm{kg}\end{array}$ & Vakili et al. (2017) \\
\hline \multirow[t]{4}{*}{ Hepatotoxicity } & $\begin{array}{l}\text { Subchronic toxicity of coumarin in } \\
\text { rats }\end{array}$ & $\begin{array}{l}\text { Vacuolar degeneration and necrosis of hepatocytes after oral } \\
\text { administration of } 0.75 \% \text { coumarin }\end{array}$ & Lake and Grasso, (1996) \\
\hline & $\begin{array}{l}\text { Acute hepatotoxicity of psoralen in } \\
\text { rats and mice }\end{array}$ & $\begin{array}{l}\text { Cholestatic liver injuries in rats only after oral administration of } \\
80 \mathrm{mg} / \mathrm{kg}\end{array}$ & Wang et al. (2019) \\
\hline & $\begin{array}{l}\text { Randomized control trial of coumarin } \\
\text { in lymphedema }\end{array}$ & $\begin{array}{l}\text { Under } 1 \% \text { incidence of hepatotoxicity in patients after oral } \\
\text { administration of } 400 \mathrm{mg} \text { coumarin for } 14 \text { months }\end{array}$ & $\begin{array}{l}\text { Casley-Smith and } \\
\text { Casley-Smith, (1995) }\end{array}$ \\
\hline & $\begin{array}{l}\text { Case report of cinnamon } \\
\text { supplements toxicity }\end{array}$ & $\begin{array}{l}\text { Hepatotoxicity with abdominal pain and liver enzymes elevation in a } \\
\text { 73-year-old patient }\end{array}$ & Brancheau et al. (2015) \\
\hline \multirow[t]{2}{*}{ Dermatological toxicity } & Case reports of fig toxicity & $\begin{array}{l}\text { Photoallergic reaction to furanocoumarins confirmed by } \\
\text { histopathological test }\end{array}$ & Bonamonte et al. (2010) \\
\hline & $\begin{array}{l}\text { Case reports of cinnamon flavored } \\
\text { products toxicity }\end{array}$ & Contact stomatitis cause by cinnamon flavored chewing-gum & Calapai et al. (2014) \\
\hline \multirow[t]{2}{*}{$\begin{array}{l}\text { Reproductive and } \\
\text { developmental toxicity }\end{array}$} & $\begin{array}{l}\text { In vitro test of coumarin on zebrafish } \\
\text { embryos }\end{array}$ & $\begin{array}{l}\text { No modifications caused by coumarin in the developing larvae or } \\
\text { their internal structures }\end{array}$ & Aspatwar et al. (2020) \\
\hline & In vivo test of coumarin on Wistar rats & No effect of coumarin on parental fertility or development of rat pups & Api et al. (2019) \\
\hline
\end{tabular}

\section{Food and Herbal Sources of Coumarin Compounds}

In nature, coumarins can be found in a free form or conjugated with other molecules like glycosides (Stringlis et al., 2019; Stassen et al., 2021). They are found in different parts of plants, such as roots, seeds, nuts, flowers and fruits of many species, being used as condiments (spices), herbal teas or medicines. In addition, coumarins can also be found in some widely used foods like oils (olive), coffee, nuts, wine, and tea (Lončar et al., 2020). Coumarins are even considered significant constituents of propolis that contribute to its pharmacological properties (esculin, daphnetin, fraxetin, umbelliferone, 4methylumbelliferone, 4-hydroxycoumarin, scoparone, coumarin or herniarin) (Hroboňová et al., 2013).

The most significant natural coumarins in the field of phytochemistry, pharmacology, medicinal chemistry, and food science, together with their vegetal sources grouped in families are listed in Table 1.

\section{SAFETY PROFILE OF NATURAL COUMARINS}

\section{General Toxicity of Natural Coumarins}

The general toxicity of natural coumarins was evaluated preclinically in several acute, subacute, subchronic or chronic tests. For coumarin, the acute oral LD50 in mice was found to be $196-780 \mathrm{mg} / \mathrm{kg}$ bw with signs of liver toxicity (Lake, 1999). In rats, acute LD50 values were $290-680 \mathrm{mg} / \mathrm{kg}$ bw after oral administration, while in guinea pigs the acute oral LD50 was $202 \mathrm{mg} / \mathrm{bw}$ (IARC, 2000). In a subchronic study, B6C3F1 mice were treated orally with $19-300 \mathrm{mg} / \mathrm{kg}$ bw coumarin for 13 weeks. Although no clinical signs of toxicity were observed, a reduction of the mean body weight gain and a centrolobular hepatocellular hypertrophy were noted for the highest dose. In Sprague-Dawley rats treated orally with $50-500 \mathrm{mg} / \mathrm{kg}$ bw coumarin for 13 weeks, several signs of liver toxicity were observed (Lake and Grasso, 1996). In a chronic study on CD-1 mice treated orally for 2 years with a diet containing 300-3,000 ppm coumarin, no signs of clinical toxicity were observed, with NOAEL of 3,000 ppm or $280 \mathrm{mg} / \mathrm{kg}$ bw/day for male mice. However, Sprague-Dawley rats administered 333-5,000 ppm coumarin for 2 years showed signs of anemia and increase of alkaline phosphatase and glutamicpyruvic transaminase (Carlton et al., 1996).

Osthole (7-methoxy-8-(3-methyl-2-butenyl)-2H-1benzopyran-2-one) was another natural coumarin tested for acute or subchronic toxicity. The acute intraperitoneal LD50 in mice was $710 \mathrm{mg} / \mathrm{kg}$ bw, the clinical signs of toxicity being hyperventilation, tremor, and photophobia. In a subchronic study, osthole was administered to Wistar rats in doses of $5-50 \mathrm{mg} / \mathrm{kg}$ bw for 45 days, by oral route. The results showed pulmonary hemorrhage and mild inflammatory processes in kidneys and liver of the animals treated with higher doses of osthole (Shokoohinia et al., 2017).

The acute toxicity of esculetin (6,7-dihydroxycoumarin) was evaluated in mouse after oral and intraperitoneal administration. The results showed a low acute toxicity with an oral LD50 of over $2000 \mathrm{mg} / \mathrm{kg}$ bw, the intraperitoneal LD50 being 1,450 mg/kg bw (Tubaro et al., 1988). The subchronic or chronic toxicity of esculetin was not assessed.

Auraptene, a coumarin from Citrus species was tested for acute oral toxicity in rats in doses of $125-2000 \mathrm{mg} / \mathrm{kg}$ bw, not 
causing mortality or clinical signs of toxicity. In a subacute test, auraptene was administered to rats orally in doses of $125-250 \mathrm{mg} / \mathrm{kg}$ bw for 28 days, with no observed hematological, histopathological, or biochemical modifications (Vakili et al., 2017). The most significant aspects concerning toxicity of natural coumarins are listed in Table 2.

\section{Hepatotoxicity of Coumarins}

Previous studies have shown that coumarin and especially its 3,4epoxide intermediate can cause vacuolar degeneration, necrosis, and apoptosis of hepatocytes in the liver of rats fed with a $0.75 \%$ coumarin diet for 4 weeks. The histopathological modifications were accompanied by significant increases in serum bilirubin and alanine aminotransferase activity (Lake and Grasso, 1996).

A recent study investigated in depth the hepatotoxic potential of psoralen, a furanocoumarin from Fructus Psoraleae (the seed of Cullen corylifolium (L.) Medik [Fabaceae]) in rats and mice. The oral administration of psoralen in doses of $80 \mathrm{mg} / \mathrm{kg}$ bw in rats and $320 \mathrm{mg} / \mathrm{kg}$ in mice produced cholestatic liver injuries in rats but not in mice. In rat liver, psoralen decreased the expression of BSEP and MRP2, suggesting an inhibition of bile acid excretion and also reduced the expression of SULT2A1, an enzyme involved in the clearance of bile acids from the organism (Wang et al., 2019).

In humans, unlike in rats, the major metabolic pathway of coumarins is 7-hydroxylation, catalyzed by CYP2A6 enzyme which leads to the formation of 7-hydroxycoumarin, excreted by urine as conjugates with glucuronic acid or sulphate anion. However, in humans with genetic polymorphism of CYP2A6, with the apparition of the inactivating CYP2A $6^{\star} 2$ allele, the 7hydroxylation is deficient, leading to the accumulation of toxic 3,4-coumarin epoxide. Although the genetic polymorphism of the mentioned isoform of cytochrome $\mathrm{P} 450$ system is more frequent in Asians, affecting $20 \%$ of the population (Mizutani, 2003), its precise correlations with known cases of coumarininduced liver toxicity were not thoroughly investigated.

In the clinical trials investigating possible beneficial effects of coumarin in lymphedema, data concerning possible hepatotoxic effects were often contradictory. Initially, in one clinical trial, two cases of hepatotoxicity were observed in 1,106 patients taking $400 \mathrm{mg}$ coumarin daily for 14 months), suggesting a low incidence (below 1\%) of this adverse effect (Casley-Smith and Casley-Smith, 1995). However, another smaller scale clinical trial highlighted an incidence rate of $9 \%$ of hepatotoxicity induced by coumarin use also for lymphedema treatment (Loprinzi et al., 1997). The large variations of the incidence of coumarin-induced hepatotoxicity observed in clinical trials are not fully understood, but they can be partially explained by differences in study designs and protocols for quantifying and interpreting the side effects.

Only a few reports signaled the apparition of hepatotoxicity in patients taking coumarin rich foods or dietary supplements. A case report study showed that cinnamon supplements used for a week by a 73-year-old patient caused a hepatitis-like syndrome with abdominal pain and liver enzymes elevation, the causality relation between the adverse effect and the ingested drug/ supplement being confirmed by Naranjo algorithm (Brancheau et al., 2015). However, other molecules present in the chemical composition of cinnamon could also contribute to the hepatotoxic effect.

\section{Anticoagulant Effect and Risk of Hemorrhage}

The anticoagulant effect of natural coumarins was firstly noticed in the first decades of the 20th century when cattle feeding on molded sweet clover (Melilotus spp.) died of severe hemorrhage. An investigation found that in sweet clover infected with specific fungi (Aspergillus spp., Penicilium spp.), the naturally present coumarin was converted by the fungi into 4-hydroxycoumarin which can spontaneously form dicoumarol, a potent anticoagulant which inhibits hepatic synthesis of several coagulation factors, acting as a vitamin $\mathrm{K}$ antagonist (Yarnell and Abascal, 2009).

However, the presence of dicoumarol in plants is relatively rare apart from molded sweet clover, being cited only in sweet vernal grass (Anthoxantum odoratum L [Poaceae]) (Polya, 2003), therefore the risk of an accidental anticoagulant effect with hemorrhage after ingesting dietary plants rich in coumarins is probably rather low. The structural characteristics (hydroxy groups) that enable dicoumarol to effectively block vitamin $\mathrm{K}$ epoxide reductase (VKOR) are not present in the molecule of coumarin. Furthermore, a small scale clinical study with coumarin administered orally to patients with chronic venous insufficiency in doses of $90 \mathrm{mg} /$ day for 6 weeks, failed to demonstrate any effect of coumarin on coagulation parameters (Köstering et al., 1985). Even though other natural coumarins could present anticoagulant effects, there are no sufficient studies to reach a clear conclusion.

\section{Dermatological Toxicity}

Among natural coumarins, several compounds like psoralen, bergapten and xanthotoxin, all belonging to furanocoumarin class, present in large concentrations in celery or limes, caused a limited number of skin phototoxic reactions in humans (Wagstaff, 1991). Thus, several cases of photoallergic reactions were also demonstrated in patients exposed to furanocoumarins from fig, the adverse reaction being confirmed by histopathological examination of patch tests (Bonamonte et al., 2010). However, a typical furanocoumarin intake from food sources is several times below the lowest dose capable of producing phototoxic effects, but the risk of exposure increases in case of inappropriate storage or processing of foods (Guth et al., 2011).

Additionally, a case of severe exacerbation of rosacea induced by cinnamon dietary supplements was reported in a 68 -year-old patient but the adverse effect could not be attributed to a specific coumarin present in the chemical composition of the supplement administered with the purpose of lowering glycemia (Campbell et al., 2008). Also, several case reports signaled the development of contact dermatitis caused by cinnamon-flavored toothpaste, chewing gum and mouthwash (Calapai et al., 2014). 
Moreover, in case of furanocoumarins, the capacity to form interstrand crosslinks with DNA and to alter DNA transcription may favor the development of skin melanoma, but further research is necessary to ascertain the validity of this hypothesis (Melough and Chun, 2018).

\section{Reproductive and Developmental Toxicity}

Several in vitro and in vivo models evaluated the reproductive and developmental toxicity of coumarins. A study on zebrafish (Danio rerio) embryos showed that coumarin caused malformations of head and tail of zebrafish embryos but the calculated LC50 was $855 \mu \mathrm{M}$, suggesting that in humans, under normal therapeutic conditions, teratogenicity could be rather low for coumarin, unlike warfarin (Weigt et al., 2012). Moreover, a recent study investigated the effects of a series of coumarin derivatives on zebrafish embryos, finding no modifications in the developing larvae and no apparent damage to their internal structures (Aspatwar et al., 2020). Additionally, an in vivo study showed that oral administration of high doses of coumarin to male and female Wistar rats, prior and during mating phase, produced no adverse effects concerning parental fertility or the development of rat pups (Api et al., 2019). In humans, no data concerning reproductive and developmental toxicity of natural coumarins have been published so far.

\section{Drug Interactions}

Coumarin derivatives are a class of chemically diverse compounds, capable of interfering with the metabolism or the effects of other drugs. Thus, several constituents from grapefruit juice like bergapten, a furanocoumarin derivative, are inhibitors of CYP3A4 liver microsomal enzyme, capable of reducing the metabolism of several associated drugs like calcium channel blockers (nitrendipine) or statins (simvastatin) with the augmentation of their adverse effects. Nevertheless, other chemical compounds like naringenin, a flavanone also present in the chemical composition of grapefruit juice are additionally responsible for this pharmacokinetic interaction (EMA, 2012).

Moreover, a recent study evaluated in vivo in rats and rabbits with alloxan-induced diabetes, the pharmacokinetic and pharmacodynamic interactions of cinnamon bark powder and pioglitazone, an oral antidiabetic drug from the class of thiazolidinediones. The results showed that cinnamon was able to inhibit CYP3A4 enzyme activity, increasing AUC of pioglitazone which is metabolized by the same isoform. Additionally, the antidiabetic effect of cinnamon, demonstrated in several studies, could increase the hypoglycemic effect of pioglitazone, an adjustment of the dose being recommended in human patients (Mamindla et al., 2017).

Another individual coumarin molecule, osthole was tested in vitro on rat and human liver microsomes regarding the effects on CYP2C11/CYP2C9 enzymes. The results showed a potent CYP2C9 inhibition in human liver microsomes with $\mathrm{Ki}$ values between 13.12 and $21.93 \mu \mathrm{M}$, also proving an influence of genotype on the pharmacokinetics of osthole. Thus, the presence of CYP2C $9 * 3$ allele caused the strongest enzymatic inhibitory activity of osthole in this experimental model (He et al., 2020).

\section{Regulatory Aspects}

A variety of foods and herbs used as nutraceuticals may have a high concentration of natural coumarins, therefore regulatory authorities around the world took legislative actions in order to avoid possible toxicities in the general public.

Initially, in the European Union, a limit of $2 \mathrm{mg} / \mathrm{kg}$ coumarin for foods prepared with natural spices and herbs was imposed. Several years later, the European Food Safety Authority (EFSA) recommended a maximum level of $0.5 \mathrm{mg} / \mathrm{kg}$ in foods. Based on various animal data, extrapolated to humans, a tolerable daily intake (TDI) of $0.1 \mathrm{mg} / \mathrm{kg}$ bw coumarin was calculated (EFSA, 2004). Nowadays, in the European Union, the presence of coumarins in food is regulated by the Decision No 1334/ 2008 of the European Parliament and Council which states that coumarin cannot be added to food as an additive. However, the Annex III of the document, stipulates that coumarin may be allowed in specific foods prepared with cinnamon as a flavor but with maximum admitted levels (e.g., $50 \mathrm{mg} / \mathrm{kg}$ for traditional bakery products and $5 \mathrm{mg} / \mathrm{kg}$ for desserts) (European Commission, 2008).

In the USA, coumarin was used as a food flavor until 1954, when its addition to food was banned by the FDA on suspicion of hepatotoxicity (Abraham et al., 2010). Therefore, any food with added coumarin is considered to be "adulterated under the act" being strictly prohibited in the US (Food and Drug Administration, 1999).

In Australia, coumarin itself was authorized for the treatment of lymphedema in 1993, but in 1996 the Australian regulatory authorities suspended the drug due to the apparition of ten cases of hepatotoxicity with two fatalities. Currently, due to the extensive use of coumarin as an ingredient in cosmetic products (sunscreens), the Australian regulatory authorities imposed a limit of maximum $0.001 \%$ coumarin in topical cosmetics, which is considered safe, with a maximum estimated exposure of below $0.02 \mathrm{mg} / \mathrm{kg}$ (Therapeutic Goods Administration, 2019).

The regulatory aspects concerning the safe use of coumarins in foods or cosmetics are quite variable worldwide. Moreover, some important aspects have not been regulated at all, like the maximum admitted level of coumarin in cinnamon itself. As a consequence, some foods, and spices with a high content of coumarin which can lead to potential toxicity are still used nowadays. The best example is the cheaper cassia cinnamon (Cinnamomum aromaticum Nees [Lauraceae]) which often replaces true cinnamon (Cinnamomum verum J. Presl [Lauraceae]) as flavor used in bakery products, generating coumarin levels over $50 \mathrm{mg} / \mathrm{kg}$, well above the upper limits set by the regulatory authorities (Yarnell and Abascal, 2009). Further studies aimed at a better understanding of the bioavailability of natural coumarins from foods and cosmetics, but also harmonization measures at international level regarding regulatory aspects are needed, for a safer use of these compounds. 


\section{CONCLUSION}

Natural coumarins present in a variety of foods and herbs are a class of chemically diverse compounds with important biological effects, useful for health promotion and the prevention of various diseases. The most important adverse effects of coumarins are represented by hepatotoxicity favored by the ingestion of large doses and possible genetic polymorphism of CYP2A6 and dermatological phototoxic

\section{REFERENCES}

Abraham, K., Wöhrlin, F., Lindtner, O., Heinemeyer, G., and Lampen, A. (2010). Toxicology and Risk Assessment of Coumarin: Focus on Human Data. Mol. Nutr. Food Res. 54 (2), 228-239. doi:10.1002/MNFR.200900281

Aisa, H. A., Xin, X.-1., and Tang, D. (2020). Chemical Constituents and Their Pharmacological Activities of Plants from Cichorium Genus. Chin. Herbal Medicines 12 (3), 224-236. doi:10.1016/J.CHMED.2020.05.001

Akkol, E. K., Genç, Y., Karpuz, B., Sobarzo-Sánchez, E., and Capasso, R. (2020). Coumarins and Coumarin-Related Compounds in Pharmacotherapy of Cancer. Cancers 12 (7), 1959-2025. doi:10.3390/cancers12071959

Ammar, S., Contreras, M. d. M., Belguith-Hadrich, O., Bouaziz, M., and SeguraCarretero, A. (2015). New Insights into the Qualitative Phenolic Profile of Ficus Carica L. Fruits and Leaves from Tunisia Using Ultra-high-performance Liquid Chromatography Coupled to Quadrupole-Time-Of-Flight Mass Spectrometry and Their Antioxidant Activity. RSC Adv. 5 (26), 20035-20050. doi:10.1039/ C4RA16746E

Ananthakrishnan, R., Chandra, P., Kumar, B., and Rameshkumar, K. B. (2018). Quantification of Coumarin and Related Phenolics in Cinnamon Samples from South India Using UHPLC-ESI-QqQLIT-MS/MS Method. Int. J. Food Properties 21 (1), 50-57. doi:10.1080/10942912.2018.1437629

Annunziata, F., Pinna, C., Dallavalle, S., Tamborini, L., and Pinto, A. (20202020). An Overview of Coumarin as a Versatile and Readily Accessible Scaffold with Broad-Ranging Biological Activities. Int. J. Mol. Sci. 21 (13), 4618. doi:10.3390/ ijms21134618

Api, A. M., Belmonte, F., Belsito, D., Biserta, S., Botelho, D., Bruze, M., et al. (2019). RIFM Fragrance Ingredient Safety Assessment, Coumarin, CAS Registry Number 91-64-5. Food Chem. Toxicol. 130 (Suppl. 1), 110522. doi:10.1016/j. fct.2019.05.030

Arcos, M. L. B., Cremaschi, G., Werner, S., Coussio, J., Ferraro, G., and Anesini, C. (2006). Tilia Cordata Mill. Extracts and Scopoletin (Isolated Compound): Differential Cell Growth Effects on Lymphocytes. Phytother Res. 20 (1), 34-40. doi:10.1002/PTR.1798

Arsenov, D., Župunski, M., Pajević, S., Nemeš, I., Simin, N., Alnuqaydan, A. M., et al. (2021). Roots of Apium graveolens and Petroselinum Crispum-Insight into Phenolic Status against Toxicity Level of Trace Elements. Plants 10 (9), 1785. doi:10.3390/PLANTS10091785

Aspatwar, A., Berrino, E., Bua, S., Carta, F., Capasso, C., Parkkila, S., et al. (2020). Toxicity Evaluation of Sulfamides and Coumarins that Efficiently Inhibit Human Carbonic Anhydrases. J. Enzyme Inhib. Med. Chem. 35 (1), 1765-1772. doi:10.1080/14756366.2020.1822829

Avula, B., Chittiboyina, A. G., Wang, Y. H., Sagi, S., Raman, V., Wang, M., et al. (2016). Simultaneous Determination of Aegeline and Six Coumarins from Different Parts of the Plant Aegle Marmelos Using UHPLC-PDA-MS and Chiral Separation of Aegeline Enantiomers Using HPLC-ToF-MS. Planta Med. 82 (06), 580-588. doi:10.1055/S-0042-103160

Bansal, Y., Sethi, P., and Bansal, G. (2013). Coumarin: a Potential Nucleus for Antiinflammatory Molecules. Med. Chem. Res. 22 (7), 3049-3060. doi:10.1007/ S00044-012-0321-6

Bhuyan, D. J., Alsherbiny, M. A., Perera, S., Low, M., Basu, A., Devi, O. A., et al. (2019). The Odyssey of Bioactive Compounds in Avocado (Persea Americana) and Their Health Benefits. Antioxidants (Basel) 8 (10), 426. doi:10.3390/ ANTIOX8100426 reactions. A better understanding of the safety profile of coumarins present in nutraceuticals is necessary for a safer use of these valuable natural compounds.

\section{AUTHOR CONTRIBUTIONS}

Conceptualization and methodology: SH, OV and LF Validation and formal analysis: CM, DM and CI.

Bonamonte, D., Foti, C., Lionetti, N., Rigano, L., and Angelini, G. (2010). Photoallergic Contact Dermatitis to 8-methoxypsoralen in Ficus Carica. Contact Dermatitis 62 (6), 343-348. doi:10.1111/J.1600-0536.2010. 01713.X

Brancheau, D., Patel, B., and Zughaib, M. (2015). Do Cinnamon Supplements Cause Acute Hepatitis? Am. J. Case Rep. 16, 250-254. doi:10.12659/AJCR. 892804

Calapai, G., Miroddi, M., Mannucci, C., Minciullo, P., and Gangemi, S. (2014). Oral Adverse Reactions Due to Cinnamon-Flavoured Chewing Gums Consumption. Oral Dis. 20 (7), 637-643. doi:10.1111/odi.12170

Campbell, T. M., Neems, R., and Moore, J. (2008). Severe Exacerbation of Rosacea Induced by Cinnamon Supplements. J. Drugs Dermatol. 7 (6), 586-587. doi:10. 1016/b978-84-8086-334-6.50203-0

Carlton, B. D., Aubrun, J. C., and Simon, G. S. (1996). Effects of Coumarin Following Perinatal and Chronic Exposure in Sprague-Dawley Rats and CD-1 Mice. Fundam. Appl. Toxicol. 30 (1), 145-151. doi:10.1006/FAAT 1996.0051

Casley-Smith, J. R., and Casley-Smith, J. R. (1995). Frequency of Coumarin Hepatotoxicity. Med. J. Aust. 162 (7), 391. doi:10.5694/J.1326-5377.1995. TB139958.X

Dini, I., and Laneri, S. (2021). Spices, Condiments, Extra Virgin Olive Oil and Aromas as Not Only Flavorings, but Precious Allies for Our Wellbeing. Antioxidants (Basel) 10 (6), 868. doi:10.3390/ANTIOX10060868

Dugrand, A., Olry, A., Duval, T., Hehn, A., Froelicher, Y., and Bourgaud, F. (2013). Coumarin and Furanocoumarin Quantitation in Citrus Peel via Ultraperformance Liquid Chromatography Coupled with Mass Spectrometry (UPLC-MS). J. Agric. Food Chem. 61 (45), 10677-10684. doi:10.1021/ JF402763T

Dugrand-Judek, A., Olry, A., Hehn, A., Costantino, G., Ollitrault, P., Froelicher, Y., et al. (2015). The Distribution of Coumarins and Furanocoumarins in Citrus Species Closely Matches Citrus Phylogeny and Reflects the Organization of Biosynthetic Pathways. PLoS ONE 10 (11), e0142757. doi:10.1371/JOURNAL. PONE.0142757

EFSA (2004). Opinion of the Scientific Panel on Food Additives, Flavourings, Processing Aids and Materials in Contact with Food (AFC) Related to Coumarin. EFSA J. 2 (12), 104. doi:10.2903/J.EFSA.2004.104

EMA (2012). Assessment report on Citrus bergamia Risso et Poiteau, aetheroleum. Available at: www.ema.europa.eu.

Esposito, S., Bianco, A., Russo, R., Di Maro, A., Isernia, C., and Isernia, P. V. (20192019). Therapeutic Perspectives of Molecules from Urtica Dioica Extracts for Cancer Treatment. Molecules 24 (15), 2753. doi:10.3390/ MOLECULES24152753

European Commission (2008). European Parliament and Council Directive No. 1334/ 2008 on the Flavourings and Certain Food Ingredients with Flavouring Properties for Use in and on Food and Amending Council Regulation (EEC) No. 1601/91, Regulations (EC) No. 2232/96 and (EC) No. 110/2008 and Directive 2000/13/EC. Official J. Eur. Community L354, 34-50. https://eur-lex.europa.eu/LexUriServ/ LexUriServ.do?uri=OJ:L:2008:354:0034:0050:en:PDF.

European Medicines Agency (2011). Chamomillae Romanae Flos. Available at: https://www.ema.europa.eu/en/medicines/herbal/chamomillae-romanae-flos.

European Medicines Agency (2017). Olea Europaea. Available at: https://www. ema.europa.eu/en/medicines/herbal/oleae-folium.

Food and Drug Administration (1999). "Food and Drugs." in US Code Federal Regulations. Title 21, Part 189, Subpart 189.130, 549. 
Forycka, A., and Buchwald, W. (2019). Variability of Composition of Essential Oil and Coumarin Compounds of Angelica Archangelica L. Herba Pol. 65 (4), 62-75. doi:10.2478/HEPO-2019-0027

Garg, S. K., Gupta, S. R., and Sharma, N. D. (1979). Coumarins from Apium graveolens Seeds. Phytochemistry 18 (9), 1580-1581. doi:10.1016/S00319422(00)98508-X

Gliszczyńska, A., and Brodelius, P. E. (2011). Sesquiterpene Coumarins. Phytochem. Rev. 11, 77-96. doi:10.1007/S11101-011-9220-6

Guo, S., Wei, H., Li, J., Fan, R., Xu, M., Chen, X., et al. (2019). Geographical Distribution and Environmental Correlates of Eleutherosides and Isofraxidin in Eleutherococcus Senticosus from Natural Populations in Forests at Northeast China. Forests 10 (10), 872. doi:10.3390/ F10100872

Guth, S., Habermeyer, M., Schrenk, D., and Eisenbrand, G. (2011). Update of the Toxicological Assessment of Furanocoumarins in Foodstuffs (Update of the SKLM Statement of 23/24 September 2004)--Opinion of the Senate Commission on Food Safety (SKLM) of the German Research Foundation (DFG). Mol. Nutr. Food Res. 55 (5), 807-810. doi:10.1002/MNFR. 201100011

Hashmi, M. A., Khan, A., Hanif, M., Farooq, U., and Perveen, S. (2015). Traditional Uses, Phytochemistry, and Pharmacology ofOlea europaea(Olive). Evidence-Based Complement. Altern. Med. 2015, 1-29. doi:10.1155/2015/541591

He, H., Zhang, Y., Zhao, D., Jiang, J., Xie, B., Ma, L., et al. (2020). Osthole Inhibited the Activity of CYP2C9 in Human Liver Microsomes and Influenced Indomethacin Pharmacokinetics in Rats. Xenobiotica 50 (8), 939-946. doi:10.1080/00498254.2020.1734882

Hroboňová, K., Lehotay, J., Čižmárik, J., and Sádecká, J. (2013). Comparison HPLC and Fluorescence Spectrometry Methods for Determination of Coumarin Derivatives in Propolis. J. Liquid Chromatogr. Relat. Tech. 36 (4), 486-503. doi:10.1080/10826076.2012.660724

IARC (2000). "Coumarin," in International Agency for Research on Cancer. Monographs on the Evaluation of Carcinogenic Risks to Humans. Editor World Health Organisation (Lyon, France: IARC), 77, 193-227.

Kaur, G. J., and Arora, D. S. (2010). Bioactive Potential of Anethum Graveolens, Foeniculum Vulgare and Trachyspermum Ammi Belonging to the Family Umbelliferae - Current Status. J. Med. Plants Res. 4 (2), 087-094. doi:10.5897/ JMPR09.018

Kenari, H. M., Kordafshari, G., Moghimi, M., Eghbalian, F., and TaherKhani, D. (2021). Review of Pharmacological Properties and Chemical Constituents of Pastinaca Sativa. J. Pharmacopuncture 24 (1), 14-23. doi:10.3831/KPI.2021.24. 1.14

Köstering, H., Bandura, B., Merten, H. A., and Wieding, J. U. (1985). The Behavior of Blood Clotting and its Inhibitors under Long Term Treatment with 5,6Benzo-Alpha-Pyrone (Coumarin). Double Blind Study. Arzneimittelforschung 35 (8), 1303-1306.

Kovač-Bešović, E. E., and Durić, K. (2003). Thin Layer ChromatographyApplication in Qualitative Analysis on Presence of Coumarins and Flavonoids in Plant Material. Bosn J. Basic Med. Sci. 3 (3), 19-26. doi:10. 17305/bjbms.2003.3523

Kriplani, P., Guarve, K., and Baghael, U. S. (2017). Arnica montana L. - a Plant of Healing: Review. J. Pharm. Pharmacol. 69 (8), 925-945. doi:10.1111/JPHP. 12724

Kumar, D., Bhat, Z. A., Kumar, V., and Shah, M. Y. (2013). Coumarins from Angelica Archangelica Linn. And Their Effects on Anxiety-like Behavior. Prog. Neuropsychopharmacol. Biol. Psychiatry 40 (1), 180-186. doi:10.1016/J.PNPBP. 2012.08.004

Lake, B. G. (1999). Coumarin Metabolism, Toxicity and Carcinogenicity: Relevance for Human Risk Assessment. Food Chem. Toxicol. 37 (4), 423-453. doi:10.1016/S0278-6915(99)00010-1

Lake, B. G., and Grasso, P. (1996). Comparison of the Hepatotoxicity of Coumarin in the Rat, Mouse, and Syrian Hamster: a Dose and Time Response Study. Fundam. Appl. Toxicol. 34 (1), 105-117. doi:10.1006/FAAT.1996.0181

Lončar, M., Jakovljević, M., Šubarić, D., Pavlić, M., Buzjak Služek, V., Cindrić, I., et al. (2020). Coumarins in Food and Methods of Their Determination. Foods 9 (5), 645. doi:10.3390/foods9050645

Loprinzi, C. L., Sloan, J., and Kugler, J. (1997). Coumarin-induced Hepatotoxicity. J. Clin. Oncol. 15 (9), 3167-3168. doi:10.1200/JCO.1997.15.9.3167
Mamindla, S., Koganti, V. S. R. G. P., Ravouru, N., and Koganti, B. (2017). Effect of Cinnamomum cassia on the Pharmacokinetics and Pharmacodynamics of Pioglitazone. Curr. Clin. Pharmacol. 12 (1), 41-49. doi:10.2174/ 1574884712666170207152020

Manderfeld, M. M., Schafer, H. W., Davidson, P. M., and Zottola, E. A. (1997). Isolation and Identification of Antimicrobial Furocoumarins from Parsley. J. Food Prot. 60 (1), 72-77. doi:10.4315/0362-028X-60.1.72

Melough, M. M., and Chun, O. K. (2018). Dietary Furocoumarins and Skin Cancer: A Review of Current Biological Evidence. Food Chem. Toxicol. 122, 163-171. doi:10.1016/J.FCT.2018.10.027

Mizutani, T. (2003). PM Frequencies of Major CYPs in Asians and Caucasians. Drug Metab. Rev. 35 (2-3), 99-106. doi:10.1081/DMR-120023681

Nahar, L., Xiao, J., and Sarker, S. D. (2021). "Introduction of Phytonutrients," in Handbook of Dietary Phytochemicals. Editors J. Xiao, S. D. Sarker, and Y. Asakawa (Singapore: Springer), 1-17. doi:10.1007/978-981-15-4148-3_2

Najda, A., Dyduch, J., Świca, K., Kapłan, M., Papliński, R., Sachadyn-Król, M., et al. (2015). Identification and Profile of Furanocoumarins from the Ribbed Celery (Apium Graveolens L Var. Dulce Mill./Pers.). Fstr 21 (1), 67-75. doi:10.3136/FSTR.21.67

Oliveros-Bastidas, A. d. J., Demuner, A. J., and Barbosa, L. C. d. A. (2013). Chemical Characterization by GC-MS and Phytotoxic Potential of Nonpolar and Polar Fractions of Seeds of Dioteryx Odorata (Aubl.) Willd. From Venezuelan Regions. Quím. Nova 36 (4), 502-506. doi:10.1590/S010040422013000400003

Önder, A. (2020). Anticancer Activity of Natural Coumarins for Biological Targets. Stud. Nat. Prod. Chem. 64, 85-109. doi:10.1016/B978-0-12-817903-1.00003-6

Ozçelik, B., Kusmenoglu, S.., Turkoz, S., and Abbasoglu, U. (2004). Antimicrobial Activities of Plants from the Apicaceae. Pharm. Biol. 42 (7), 526-528. doi:10. 3109/13880200490893311

Petrulová-Poracká, V., Repčák, M., Vilková, M., and Imrich, J. (2013). Coumarins of Matricaria Chamomilla L.: Aglycones and Glycosides. Food Chem. 141 (1), 54-59. doi:10.1016/J.FOODCHEM.2013.03.004

Polya, G. M. (2003). Protein and Non-protein Protease Inhibitors from Plants. Stud. Nat. Prod. Chem. 29, 567-641. doi:10.1016/S1572-5995(03)80015-7

Rebey, I. B., Zakhama, N., Karoui, I. J., and Marzouk, B. (2012). Polyphenol Composition and Antioxidant Activity of Cumin (Cuminum Cyminum L.) Seed Extract Under Drought. J. Food Sci. 77 (6), C734-C739. doi:10.1111/J. 1750-3841.2012.02731.X

Repajić, M., Cegledi, E., Zorić, Z., Pedisić, S., Elez Garofulić, I., Radman, S., et al. (2021). Bioactive Compounds in Wild Nettle (Urtica Dioica L.) Leaves and Stalks: Polyphenols and Pigments upon Seasonal and Habitat Variations. Foods 10 (1), 190. doi:10.3390/FOODS10010190

Sarker, S. D., and Nahar, L. (2017). "Progress in the Chemistry of Naturally Occurring Coumarins," in Progress in the Chemistry of Organic Natural Products. Editors A. Kinghorn, H. Falk, S. Gibbons, and J. Kobayashi (Cham: Springer), 106, 241-304. doi:10.1007/978-3-319-59542-9_3

Sharifi-Rad, J., Cruz-Martins, N., López-Jornet, P., Lopez, E. P.-F., Harun, N., Yeskaliyeva, B., et al. (2021). Natural Coumarins: Exploring the Pharmacological Complexity and Underlying Molecular Mechanisms. Oxidative Med. Cell Longevity 2021, 1-19. doi:10.1155/2021/6492346

Shokoohinia, Y., Bazargan, S., Miraghaee, S., Javadirad, E., Farahani, F., and Hosseinzadeh, L. (2017). Safety Assessment of Osthole Isolated from Prangos Ferulacea: Acute and Subchronic Toxicities and Modulation of Cytochrome P450. Jundishapur J. Nat. Pharm. Prod. 12 (3), 12. doi:10.5812/JJNPP.63764

Srikrishna, D., Godugu, C., and Dubey, P. K. (2018). A Review on Pharmacological Properties of Coumarins. Mini Rev. Med. Chem. 18 (2), 113-141. doi:10.2174/ 1389557516666160801094919

Stassen, M. J. J., Hsu, S. H., Pieterse, C. M. J., and Stringlis, I. A. (2021). Coumarin Communication along the Microbiome-Root-Shoot Axis. Trends Plant Sci. 26 (2), 169-183. doi:10.1016/J.TPLANTS.2020.09.008

Stringlis, I. A., de Jonge, R., and Pieterse, C. M. J. (2019). The Age of Coumarins in PlantMicrobe Interactions. Plant Cel Physiol 60 (7), 1405-1419. doi:10.1093/PCP/PCZ076

Sun, W., Shahrajabian, M. H., and Cheng, Q. (2019). Anise (Pimpinella Anisum L.), a Dominant Spice and Traditional Medicinal Herb for Both Food and Medicinal Purposes. Cogent Biol. 5 (1), 1673688. doi:10.1080/23312025.2019.1673688

Therapeutic Goods Administration (2019). Australian Government, Department of Health, Therapeutic Goods Administration. Coumarin for Use in Topical Listed Medicines. Available at: https://www.tga.gov.au/sites/default/files/safetyreview-coumarin-listed-medicines.pdf. 
Tubaro, A., Del Negro, P., Ragazzi, E., Zampiron, S., and Della Loggia, R. (1988). Antiinflammatory and Peripheral Analgesic Activity of Esculetin In Vivo. Pharmacol. Res. Commun. 20 (Suppl. 5), 83-85. doi:10.1016/S0031-6989(88)80847-6

Vakili, T., Iranshahi, M., Arab, H., Riahi, B., Roshan, N. M., and Karimi, G. (2017). Safety Evaluation of Auraptene in Rats in Acute and Subacute Toxicity Studies. Regul. Toxicol. Pharmacol. 91, 159-164. doi:10.1016/J. YRTPH.2017.10.025

Vasudeva, N., Das, S., and Sharma, S. (2016). Cichorium Intybus: A Concise Report on its Ethnomedicinal, Botanical, and Phytopharmacological Aspects. Drug Dev. Ther. 7 (1), 1. doi:10.4103/2394-6555.180157

Venugopala, K. N., Rashmi, V., and Odhav, B. (2013). Review on Natural Coumarin lead Compounds for Their Pharmacological Activity. Biomed. Res. Int. 2013, 963248. doi:10.1155/2013/963248

Wagstaff, D. J. (1991). Dietary Exposure to Furocoumarins. Regul. Toxicol. Pharmacol. 14 (3), 261-272. doi:10.1016/0273-2300(91)90029-U

Wang, Y., Zhang, H., Jiang, J. M., Zheng, D., Chen, Y. Y., Wan, S. J., et al. (2019). Hepatotoxicity Induced by Psoralen and Isopsoralen from Fructus Psoraleae: Wistar Rats Are More Vulnerable Than ICR Mice. Food Chem. Toxicol. 125, 133-140. doi:10.1016/J.FCT.2018.12.047

Wang, Y. H., Avula, B., Nanayakkara, N. P., Zhao, J., and Khan, I. A. (2013). Cassia Cinnamon as a Source of Coumarin in Cinnamon-Flavored Food and Food Supplements in the United States. J. Agric. Food Chem. 61 (18), 4470-4476. doi:10.1021/JF4005862

Weigt, S., Huebler, N., Strecker, R., Braunbeck, T., and Broschard, T. H. (2012). Developmental Effects of Coumarin and the Anticoagulant Coumarin Derivative Warfarin on Zebrafish (Danio rerio) Embryos. Reprod. Toxicol. 33 (2), 133-141. doi:10.1016/j.reprotox.2011.07.001

Yang, I. J., Lee, D. U., and Shin, H. M. (2015). Anti-inflammatory and Antioxidant Effects of Coumarins Isolated from Foeniculum Vulgare in Lipopolysaccharide-Stimulated Macrophages and 12-O-Tetradecanoylphorbol-13-Acetate-Stimulated Mice.
Immunopharmacol Immunotoxicol 37 (3), 308-317. doi:10.3109/08923973.2015. 1038751

Yarnell, E., and Abascal, K. (2009). Plant Coumarins: Myths and Realities. Altern. Complement. Therapies 15 (1), 24-30. doi:10.1089/ACT.2009. 15104

Zahran, E. M., Abdelmohsen, U. R., Khalil, H. E., Desoukey, S. Y., Fouad, M. A., and Kamel, M. S. (2020). Diversity, Phytochemical and Medicinal Potential of the Genus Ocimum L. (Lamiaceae). Phytochem. Rev. 19 (4), 907-953. doi:10. 1007/S11101-020-09690-9

Zang, Y. (2020). Pharmacological Activities of Coumarin Compounds in Licorice: A Review. Nat. Product. Commun. 15 (9), 1934578X2095395. doi:10.1177/ 1934578X20953954

Conflict of Interest: The authors declare that the research was conducted in the absence of any commercial or financial relationships that could be construed as a potential conflict of interest.

Publisher's Note: All claims expressed in this article are solely those of the authors and do not necessarily represent those of their affiliated organizations, or those of the publisher, the editors and the reviewers. Any product that may be evaluated in this article, or claim that may be made by its manufacturer, is not guaranteed or endorsed by the publisher.

Copyright (c) 2022 Heghes, Vostinaru, Mogosan, Miere, Iuga and Filip. This is an open-access article distributed under the terms of the Creative Commons Attribution License (CC BY). The use, distribution or reproduction in other forums is permitted, provided the original author(s) and the copyright owner(s) are credited and that the original publication in this journal is cited, in accordance with accepted academic practice. No use, distribution or reproduction is permitted which does not comply with these terms. 